\title{
Irreducible incoherence and Intelligent Design: a look into the conceptual toolbox of a pseudoscience
}

\begin{abstract}
The concept of Irreducible Complexity (IC) has played a pivotal role in the resurgence of the creationist movement over the past two decades. Evolutionary biologists and philosophers have unambiguously rejected the purported demonstration of "intelligent design" in nature, but there have been several, apparently contradictory, lines of criticism. We argue that this is in fact due to Michael Behe's own incoherent definition and use of IC. This paper offers an analysis of several equivocations inherent in the concept of Irreducible Complexity and discusses the way in which advocates of the Intelligent Design Creationism (IDC) have conveniently turned IC into a moving target. An analysis of these rhetorical strategies helps us to understand why IC has gained such prominence in the IDC movement, and why, despite its complete lack of scientific merits, it has even convinced some knowledgeable persons of the impending demise of evolutionary theory.
\end{abstract}

\section{Introduction}

UNTIL ITS DRAMATIC legal defeat in the Kitzmiller v. Dover case, Intelligent Design Creationism (IDC) had been one of the most successful pseudosciences of the past two decades, at least when measured in terms of cultural influence. It is interesting to explore the way this species of creationism had achieved this success, notwithstanding its periodic strategic setbacks as well as its complete lack of scientific merits. Of course, a full explanation would include religious, socio-political, and historical reasons; instead, in this paper, we will take a closer look at the conceptual toolbox and rhetorical strategies of the ID creationist. As a case study, we will concentrate on the central concept of "irreducible complexity" (IC), but other examples can be found that support our assertions. Our analysis shows that the conceptual equivocations inherent in the concept of IC - in particular its potential to function as a moving target in discussions (Boudry and Braeckman 2010) — may help further our understanding of the superficial appeal of the design argument based on IC, which is only the most recent in a long series of creationist challenges mounted against evolutionary theory.

\section{Irreducible Complexity}

In 1996, biochemist and ID proponent Michael Behe introduced the infamous concept of irreducible complexity (IC) in his book Darwin's Black Box. Although Behe's critics univocally agreed that he failed to demonstrate evidence of "intelligent design" in nature, there have been several, seemingly inconsistent lines of criticism. Some evolutionary scientists claim that biological systems do sometimes exhibit IC as Behe defines it, but they deny that this poses a problem for evolutionary theory (e.g. Orr 1997; Shanks and Joplin 
1999; Miller 2000), while others maintain that Behe has never demonstrated the existence of bona fide instances of IC in nature (e.g. Pigliucci 2002; Forrest and Gross 2007). Pennock (1999, pp. 264-272)concurs with this criticism but grants the possible existence of biological IC systems, arguing that, in any case, these would not threaten evolutionary theory.

We propose that this seemingly contradictory criticism is in fact due to Behe's own disjointed definition and misleading use of IC. First, we introduce Behe's concept and briefly recount the most important empirical objections against it. Then, we analyse the conceptual equivocations inherent in Behe's approach on several levels (see also Dunkelberg 2003). Finally, we argue that these kinds of equivocations allow Behe and his IDC fellows to make a moving target out of their theory, hence serving to insulate it against criticism.

\section{The Evolution of Irreducible Complexity}

The concept of IC has an interesting "evolutionary" pedigree (Forrest and Gross 2007, p. 302). In the 1970s and 1980s, young-Earth creationists used similar terms to describe biological systems that were alleged obstacles to evolutionary theory. In 1974, Henry Morris, founder of the Institute for Creation Research and father of the Creation-Science movement, argued in his influential book Scientific Creationism that "The problem is simply whether a complex system, in which many components function unitedly together, and in which each component is uniquely necessary to the efficient functioning of the whole, could ever arise by random processes" (Morris 1974, p. 59). In 1980, young-earth creationist Ariel Roth argued that "Creation and various other views can be supported by the scientific data that reveal that the spontaneous origin of the complex integrated biochemical systems of even the simplest organisms is, at best, a most improbable event" (Roth 1980, p. 83). Behe has simply adapted these creationist notions to his own ends. Consider his definition of IC in Darwin's Black Box:

By irreducibly complex I mean a single system composed of several well-matched, interacting parts that contribute to the basic function, wherein the removal of any one of the parts causes the system to effectively cease functioning. An irreducibly complex system cannot be produced directly (that is, by continuously improving the initial function, which continues to work by the same mechanism) by slight, successive modifications of a precursor system, because any precursor to an irreducibly complex system that is missing a part is by definition non-functional. An irreducibly complex biological system, if there is such a thing, would be a powerful challenge to Darwinian evolution (Behe 2006, p. 39).

\section{Redundant and Irreducible Complexity}

Behe then proceeds to argue that many biological systems exhibit IC, especially at the subcellular level (e.g., the bacterial flagellum). However, many critics have noted that the components of a typical biological system manifest considerable functional overlaps and 
redundancy. Contrary to Behe's assertions, living systems are often quite robust to perturbations, despite, or even because of, their complexity (Ciliberti, Martin et al. 2007). Overall these system exhibit what has been termed "redundant complexity" (Shanks and Joplin 1999). For example, if we eliminate one or even several elements from the blood clotting cascade, which Behe cites as an instance of an IC system, the system still manages to perform its function, albeit not as swiftly or efficiently as before. From the perspective of evolutionary theory, this is hardly surprising; natural selection is a clumsy and opportunistic process that tinkers with the available material. Thus, the widespread phenomenon of redundant complexity makes it perfectly clear that evolution by natural selection can gradually produce increasingly complex systems without the guidance of an intelligent designer (see below).

\section{Conceptual Double Life}

To be sure, it is not difficult to find examples of biochemical systems in which the removal of just one part damages the whole system. But consider Behe's phrases "effectively ceases functioning" and "by definition non-functional." There are two possible reconstructions of his definition: 1) the term "functioning" refers exclusively to the basic function currently performed by the whole system (e.g., the rotary motion of the bacterial flagellum) and does not pertain to other possible functions, in other contexts, when one or more components are removed; and 2) the phrases "effectively ceases functioning" and "nonfunctional" include any function that the impaired system or one of its components may perform in other contexts. In principle, it is not very hard to discover whether a system exhibits IC in the first, weak sense. Leaving aside the ambiguity regarding the natural "parts" into which the system must be decomposed (Dunkelberg 2003; Sober 2008, pp. 135-160), it suffices to knock out these parts one after the other to see if the system can still perform its basic function. Again, evolution by natural selection is perfectly capable of producing complex functional systems exhibiting IC in this weak sense. For example, Lenski et al. (2003) used a population of "digital organisms" (i.e., computer programs) to simulate the evolution of a complex functional system. By performing a series of knockout experiments on one of the complex functions that emerged from their simulation, Lenski et al. were able to determine how many genomic "instructions" were involved in its functioning. The researchers found that the function "depends on many interacting components" (2003:141), the removal of any of which causes the system to break down.

In fact, only an IC system in the second, strong sense would be an obstacle to evolutionary theory, because it would rule out evolutionary precursor systems and function shifts of the system's components. However, it is hard to see how Behe could even begin to demonstrate the existence of such a system without defaulting to the classical "argument from ignorance" (Pigliucci 2002, p. 67). Interestingly, Behe has disingenuously taken advantage of this very ambiguity in answering his critics. 
In his initial definition, Behe seems to intend the weak interpretation, but he then proceeds to use the concept in a line of reasoning that only makes sense under the strong interpretation. Precisely because the bacterial flagellum is IC, Behe tells us, it could not have evolved by means of random mutation and natural selection. However, when critics object that the system's components may well be able to perform other functions in other contexts, thus pointing to the possibility of indirect evolutionary pathways, Behe switches back to the weak definition and claims that his critics have misrepresented his argument.

\section{A Conceptual Mousetrap}

Robert Pennock (1999, p. 267) objected to Behe's design argument that "even if a system is irreducibly complex with respect to one defined basic function, this in no way implies that nearby variations might not serve other nearby functions". Reasonably, Pennock construes Behe's argument in a sense that is intended to preclude any functional intermediate on a direct or indirect evolutionary path to the current system:

Behe claims that there could never be any functional intermediates that natural selection could have selected for on the way to any irreducibly complex system, but he can't get the empirical conclusion from his "by definition" conceptual argument" (Pennock 1999, pp. 267-268)

Pennock's reasoning is correct, of course, but in the afterword to the tenth anniversary edition of Darwin's Black Box, Behe (2006, p. 258) retorts that "Pennock [simply] substituted his own concept of irreducible complexity for mine," whereupon he shifts back to the weak version of the concept, which merely rules out direct improvements on the system: "On the contrary, on page 40, I point out that, although irreducible complexity does rule out direct routes, it does not automatically rule out indirect ones" (see also Ratzsch 2005). Thus, Behe protests that Pennock has "overlooked important qualifications" (Behe 2001, p. 707) and has simply "constructed his own rigid straw man definition for IC." But Behe himself has boldly stated that any IC system is a "powerful challenge to Darwinian evolution" (2006, p. 39), and that "[w]e know of no other mechanism, including Darwin's, which produces such complexity" (1996, p. 25). Thus, the fact that Behe's own qualifications are inconsistent with his boastful presentation of IC as a major stumbling block for evolution is hardly Pennock's problem. Behe did acknowledge that Pennock exposed another weakness in the definition of IC, owing to its focus on already functioning systems rather than on the evolutionary development of such systems. Although he promised to "repair this defect in future work" (Behe 2001, p. 695), so far Behe has not lived up to that promise, instead seeming to ignore the problem altogether.

The neglect of evolutionary development in Behe's definition is hardly a trivial matter, however, and his concession concerning indirect routes is quite an important one, which seems to be completely absent from his original definition (see also Sober 2008, pp. 161-162). 
As early as the beginning of the 20th century, geneticist Herman Muller explained how biological systems that depend on the complex "interlocking" actions of many different components could come about by evolutionary processes: "Many of the characters and factors which, when new, were originally merely an asset finally became necessary because other necessary characters and factors had subsequently become changed so as to be dependent on the former" (Muller 1918, pp. 463-464). Thus, redundant complexity can eventually generate IC (under the weak interpretation). More recently, biochemist and molecular biologist A. G. Cairns-Smith proposed the analogy of "scaffolding" in the construction of an arch to explain the evolution of systems that are IC according to Behe (Cairns-Smith 1986; see also Orr 1997; Pennock 2000). A classical stone arch is IC in the weak sense, because the structure will collapse as soon as one removes either the keystone or one of the other stones. The support of scaffolding is necessary in building a stone arch, but once the arch is completed, the scaffolding can be safely removed. In a similar vein, a biochemical structure may have functioned as a scaffold in the evolution of an IC system before becoming dispensable and disappearing. That is, "Before the multitudinous components of present biochemistry could come to lean together they had to lean on something else" (Cairns-Smith 1986, p. 61).

Behe has performed a similar conceptual sleight of hand in dealing with the objections of molecular biologist Kenneth Miller (2000). Miller accepts that some biological systems are IC as Behe defines it (weak version), but he objects to the anti-evolutionist conclusions that Behe derives from IC. As a counterexample of Behe's claim, Miller offers a plausible reconstruction of the evolutionary history of the five-part auditory apparatus in mammals, which he argues fulfils the definition of IC. Miller demonstrates that the individual parts of the auditory apparatus - mallens, incus, and stapes - evolved from the rear portion of the reptilian jaw. It is important to note that before they migrated to the middle ear and were adapted for their new purposes, these structures were indeed perfectly functional. Therefore, Miller concludes that Behe's statement (2006, p. 39) that "any precursor to an irreducibly complex system that is missing a part is by definition non-functional" is plainly wrong. Miller challenges strong IC and demonstrates the crucial point, which is that the "interlocking necessity [of the parts of the final working system] does not mean that the system could not have evolved from a simpler version" (2000, p. 139).

Behe, however, has responded by asserting that Miller "concocted his own, private definition of irreducible complexity, and then argued against that" (2006, p. 259). It is quite possible, he goes on to explain, that individual components of an IC system can perform functions in different contexts. Thus, according to Behe, (2006, p. 260) Miller has "redefined irreducible complexity to mean that none of the component parts of an IC system could have its own function separate from the system".

Yet again, the equivocation is in Behe's definition, not in Miller's criticism. Bearing in mind that Behe treats IC as if it were an insurmountable obstacle for evolution, which is already clear from the very wording of the term "irreducible," the critic naturally confronts Behe's claim of "non-functionality" by pointing to the different functions performed by evolutionary precursors of IC systems, which may or may not have contained parts of the current system. 
After all, if we bear in mind that biological systems can be adapted over the course of evolution for another function than that for which they were originally selected-for instance, by being integrated as part of a new system performing a different function-then Behe's non-functionality claim becomes either trivial (weak version) or plainly wrong (strong version).

\section{Dembski's Conceptual Remedy}

In No Free Lunch (2002), Behe's creationist ally William Dembski proposed to remedy the conceptual problems of IC. Dembski believes that the concept of IC is "salvageable" (2002, p. 280), and after a series of modifications, he arrives at the following new definition:

Definition $\mathrm{IC}_{\text {final }}$ - A system performing a given basic function is irreducibly complex if it includes a set of well-matched, mutually interacting parts such that each part in the set is indispensable to maintaining the system's basic, and therefore original, function. The set of these indispensable parts is known as the irreducible core of the system (Dembski 2002, p. 285, emphasis in original).

Accordingly, Dembski argues, the IC of a system is a straightforward empirical question:

Individually knocking out each protein constituting a biochemical system will determine whether function is lost. If it is, we are dealing with an irreducibly complex system (Dembski 1999, p. 148).

Clearly, Dembski has "fine-tuned" the concept of IC in the direction of the weak interpretation, restricting the definition to the basic, original function of the system. His updated version has the merit of conceptual clarity (but see Perakh 2002), but, in remedying Behe's conceptual ambiguity, Dembski actually takes the sting out of the whole argument. IC thus conceived is perfectly consistent with indirect and circuitous routes, scaffolding, and exaptations. So what is all the fuss about? The collapse of IC in Dembski's hands illustrates that the conceptual ambiguity he was trying to salvage was actually very convenient for Behe.

\section{Never Enough}

Despite Dembski's remedy, other equivocations in the concept of IC have yet to be resolved. Having failed to provide an objective criterion that makes evolutionary accounts impossible, the IDC proponent retreats to a weaker probabilistic claim; as the number of individual components in an IC system increases, the plausibility of a gradual succession of 
slight modifications becomes vanishingly small. "The strength of the inference depends on the number of parts, and the more intricate and sophisticated the function, the stronger is our conclusion of design" (Behe 2006, p. 265). Leaving aside the problems regarding this alleged correlation between the numbers of parts and the strength of the design inference, which are amply documented by Pennock (1999, p. 270), we still seem to be left with a testable statement. If we can find a well-functioning precursor for one of the systems discussed by Behe (or for one of its components), or if we can construct a plausible evolutionary pathway for one of Behe's examples, the "probability" argument collapses.

Behe's claim has indeed been tested against the facts and has been found wanting (Miller 2000; Lenski, Ofria et al. 2003; Young and Edis 2006; Forrest and Gross 2007). In response to these demonstrations, however, IDC proponents belatedly "reinterpret" their initial claims in order to lift them out of the critic's reach. A first strategy to this end consists of shifting the burden of proof from plausible evolutionary pathways to the actual evolutionary story, and thus to protest that the broad outlines of a plausible evolutionary account amount to nothing more than Darwinian wishful thinking and speculation. The same bait-and-switch technique can be discerned here: IC is constantly boasted as a point of principle for ruling out the possibility of evolutionary explanations, but as soon as it is challenged on that ground through a discussion of plausible evolutionary scenarios, ID creationists contend that they were talking about actual evolutionary pathways all along.

When they are confronted with tangible evidence of actual evolutionary history, IDC theorists resort to a second strategy, shifting their design claims to the remaining parts of the evolutionary puzzle, as if the "real" problem was always there. For example, Kenneth Miller (2004) beautifully demonstrated the structural similarities between one component of the flagellum and the so-called type III-secretory system. He convincingly argued that the former is a very plausible evolutionary precursor of the latter, which has been co-opted by evolution to perform a new function (see also Pallen and Matzke 2006). In response to this embarrassing demonstration, Behe (2001, pp. 689-690) simply shifted his attention to the complexity of the newly discovered system by itself, while at the same time stubbornly insisting that the assemblage of these precursors into the flagellum system is still impossible without the helping hand of a Designer (Behe 2004, p. 359).

In light of these evasions, one may wonder whether there is any amount of comparative genetic evidence, or any level of evolutionary reconstruction, that would make Behe and his allies abandon their design claims. Because of the sloppiness of the probabilistic IC claim, which is not based on any serious quantification of probabilities, IDC theorists can continue to raise the evidential bar up to a point where the concept of IC is lifted outside of the empirical domain altogether. Indeed, when pressed on the available scientific knowledge of a particular complex system that he cites, Behe has made it clear that only a complete, quantitative, and fully-detailed description of what actually happened over the course of the ages would convince him of its evolutionary origin (Behe 2007). In his testimony at the Dover trial, Behe conceded: 
Not only would I need a step-by-step, mutation by mutation analysis, I would also want to see relevant information such as what is the population size of the organism in which these mutations are occurring, what is the selective value for the mutation, are there any detrimental effects of the mutation, and many other such questions. (2005, p. 19)

But this is an absurd demand, which is never met in any other scientific domain, and is certainly not met by ID creationists themselves when they propose "design" as an alternative explanation. Indeed, despite his demand for such a high level of evidence for the evolution of what he claims are IC systems, Behe himself has been completely unwilling to flesh out his design hypothesis to any degree at all, insisting that the motives and character of the designer are in fact inscrutable, and he provides us with no clue as to his modus operandi. As for Behe's request for fully detailed knowledge about evolutionary history, Pigliucci (2002, p. 240) has warned biologists not to be overconfident in taking up creationist challenges, and not to mistake partial reconstructions and plausible scenarios for a complete understanding of evolutionary development. Indeed, evolutionary theorists are better advised to explain why the burden of proof insisted on by creationists is absurd, and to point out that scientific knowledge will never be complete in this respect.

In any case, what is disingenuous in Behe's presentation is that this preposterous challenge to offer a complete and step-by-step evolutionary account of IC systems is not spelled out from the beginning, but is a belated revision of his original claim, based on ambiguities in his definition of IC. In Darwin's Black Box, Behe leaves us with the impression that the unevolvability claim of IC is in principle easy to challenge, but when his critics take up the gauntlet, as we saw in the discussion with Pennock and Miller, Behe simply dodges and weaves like a hunted rabbit. Thus, what remains of Behe's argument boils down to the same old "argument from personal incredulity" (Dawkins 1991, p. 38), which is a far cry from the "objective criterion" for design that IDC theorists had promised.

It is interesting to note that the same pattern of reasoning has always been rampant in traditional creationist arguments regarding the so-called "gaps" in the fossil record. Creationists claim that they would readily accept evolution if only the "missing links" between the taxonomic groups turned up in the fossil record, but, whenever such a fossil is found, they complain that the intermediate is not really the ancestor of the present organisman impossible demand for the fossil record-or even that Darwinists now face an ever bigger hurdle, because they are left with two gaps to explain. The latter principle has been coined “Gish's law” by geologist Robert S. Dietz (1983), after young-earth creationist Duane Gish.

\section{Falsification and Failure of Instantiation}

The design argument based on IC always allows for a final retreat. Suppose we can provide IDC proponents with a fully-detailed description of the evolution of the bacterial 
flagellum. Even if their stubborn insistence on the flagellum's exhibiting IC would at that point become absurd even in their own eyes (although one can never be too sure about that), they would surely regard this not as a refutation of IDC as such, but merely as a specific case in which IC turns out not to be instantiated. The expectation that this particular biological system would exhibit IC and hence be one of those unmistakable traces of design would simply be disappointed, and the search for new obstacles to evolution could begin.

In fact, this is what the history of the creationist movement is all about: if the case for evolution by natural selection becomes too overwhelming, creationists typically drop their favourite examples of complexity and come up with fresh ones, whose evolutionary origins are still relatively obscure (Pennock 1999, pp. 171-172). For example, the traditional objection against evolution used to be the vertebrate eye. Nowadays, the evolutionary development of the vertebrate eye is well-understood and it has become an outdated argument against evolutionary theory. It is not even a particularly difficult example for evolutionary theorists, as it involves relatively straightforward selection pressures.

As the evolutionary history of the bacterial flagellum and the blood clotting system are being unravelled, the next generation of creationists can always disclaim the examples of their IDC forebears, and a new round of pointless arguments can begin-although they would at least have to admit that their former "design criterion" was defective because it generated false positive ${ }^{\mathrm{s}}$. However, the retreat into unknown territory cannot go on indefinitely. In fact, as Robert Pennock (1999, p. 171) remarked, the current preoccupation of IDC theorists with invisible biochemical niceties such as the propeller system of $E$. coli bacteria indicates "just how far creationists have had to retreat to find significant explanatory gaps in evolutionary theory".

\section{Moving the Goalposts}

The most conspicuous feature of the concept of IC is not so much its ambiguity, but the discrepancy between what it seems to promise and what it eventually delivers, as far as testable empirical claims are concerned. On first reading Behe's argument, the unsuspecting reader may be left with the impression that Behe really sticks his neck out and presents evolutionists with a clear empirical challenge. However, this apparent rigour of the IC concept as an objective criterion for design, which arguably makes it appealing to anti-evolutionists, evaporates upon closer inspection. Under the weak interpretation, the concept describes a well-known phenomenon in the living world that is unproblematic for evolutionary theory. Under the strong interpretation, IC systems would indeed confront evolutionary theory with serious problems, but Behe has not given us an inkling of how we could ever demonstrate whether a system qualifies as IC in this sense. Indeed, it would require ruling out any conceivable evolutionary history, and would thus amount to showing that no part or precursor of the system in question is able to perform any other function, in any other situation and at any time. 
This allows for an interesting bait-and-switch strategy, which one could summarize as follows: "First, present evidence for weak IC in the living world, then pretend that strong IC has been demonstrated and continue to equate IC with 'unevolvability.' If challenged on empirical grounds, jump back to the weak version and claim that your critics are misrepresenting your argument. Switch the IC claim to subsystems and assembly of components, keep raising the standards of evidence, and reassert that all this directly follows from the simple objective criterion of IC. Finally, when really pressed against the wall, give up this particular system and quickly find a new one. Repeat the circle ad libitum."

\section{Further Equivocations}

Behe's concept of IC is not the only instance of conceptual equivocation in the IDC literature. Two examples may be the subject of further research. First, when writing about "information," William Dembski surreptitiously switches between its standard interpretation in information theory, in which it is a measure of the randomness in a system, and its colloquial use in the sense of "meaningful message" (Perakh 2004, pp. 64-75). This ambiguity allows him to fool the reader into believing that the "information" encoded in DNA, for example, points in the direction of an intelligent designer. For a similar discussion regarding the term "teleological", see Blancke et al. (2010).

A second example is the IDC response to the series of mousetraps that John McDonald devised to refute the claim that gradualist evolution of IC systems is impossible (with the mechanical mousetrap as a paradigm example). Instead of admitting to their lack of imagination, IDC theorists have responded by complaining about the intelligent guidance used in constructing this evolutionary progression of mousetraps (Behe 2004, pp. 364-366). Amazingly, they argue that McDonald's mousetraps unwittingly demonstrate that an IC system always requires an Intelligent Designer. But this reply illegitimately shifts the discussion - which is actually about a human artifact and thus is, in any case, irrelevantfrom the IC of a system to the blind and unguided character of evolution.

Conclusion

Although the IDC movement has been damaged, in terms of its credibility, by the Kitzmiller v. Dover case, it does not show clear signs of disappearing. As Forrest and Gross note in an afterword to their meticulous study of IDC's politics and religious ideology, the movement has simply changed its strategy once again. After their recent legal setbacks, they have been forced to drop overt talk of "intelligent design" and to adopt code words like "academic freedom" and teaching "the strengths and weaknesses of evolution" instead (Forrest and Gross 2007, p. 337). "Creationists never give up. They merely change their strategy with each new defeat" (Forrest and Gross 2007, p. 309). 
As was apparent from its conception, the rapid success of the IDC movement was never driven by its arguments but by its religious ideology, which was epitomized in the socalled Wedge document of IDC's home base, the Discovery Institute (Forrest and Gross 2007). Beyond religious motivation, one can point to sociological, cultural, and political factors to account for the remarkable success of IDC (outside the scientific community, to be sure), and it is plausible that the persistence of anti-evolutionary sentiments and the continuing appeal of the design argument is also a function of deeply rooted cognitive dispositions and hard-to-shake teleological intuitions about the world (Kelemen and Rosset 2009; Kelemen 2004).

Anti-evolutionism can take many different forms, however, and not all of them can achieve equal cultural success. In this paper, we have analyzed some of the rhetorical strategies that Behe and other IDC theorists have used for presenting their challenge to evolution and for deflecting valid criticism. On the one hand, we claim that Behe's presentation of IC has the appearance of an objective design criterion, which makes it superficially more respectable than the age-old "argument from personal incredulity." On the other hand, the equivocations that are built into the definition of IC allow it to be used as a moving target (Boudry and Braeckman 2010), and as a kind of conceptual chimera that is hard to pin down by critics. These considerations partly explain why the concept of IC was hailed by the movement as the ultimate challenge to evolutionary theory, and why, despite its complete lack of scientific merits, it has convinced even some knowledgeable persons of the impending demise of evolutionary theory. As Robert Pennock (1999, p. 1) wrote:

We think of creationism as a cluster of ideas that reproduces itself by spreading from mind to mind and struggling with competing ideas for a home among a person's beliefs. Sometimes it loses out to more powerful rival ideas, but sometimes it finds receptive mental soil, takes root and waits to be passed on again.

Indeed, in the past two decades the concept of IC seems to have found receptive mental soil among anti-evolutionists. An analysis of the convenient conceptual equivocations inherent in IC, as well as of the rhetorical strategies with which IC has been presented, helps us to understand this remarkable fertility. 


\section{Bibliography}

Kitzmiller vs Dover Area School District. Transcript of proceedings. Afternoon session (U.S. District Court for the Middle District of Penssylvania 2005)

Behe MJ (1996, October 29) Darwin Under the Microscope. The New York Times, p. 25,

Behe MJ (2001) Reply to my critics: A response to reviews of Darwin's Black Box: the biochemical challenge to evolution. Biol Phil 16(5):683-707

Behe MJ (2004) Irreducible complexity: obstacle to Darwinian evolution. In W. Dembski and M. Ruse (Eds.), Debating design: from Darwin to DNA (pp 352-370). New York, Cambridge University Press

Behe MJ (2006) Darwin's black box : the biochemical challenge to evolution (10th Anniversary Edition). New York, NY, Simon and Schuster

Behe MJ (2007) The edge of evolution : the search for the limits of Darwinism. New York (N.Y.), Free press

Blancke S, Boudry M, et al. (2010) Simulation of biological evolution under attack, but not really: a response to Meester. Biol Phil

Boudry M and Braeckman J (2010) Immunizing strategies \& epistemic defense mechanisms. Philosophia. doi:10.1007/s11406-010-9254-9

Cairns-Smith AG (1986) Seven clues to the origin of life: a scientific detective story. Cambridge, UK, Cambridge University Press

Ciliberti S, Martin OC, et al. (2007) Innovation and robustness in complex regulatory gene networks. Proceedings of the National Academy of Sciences 104(34):13591

Dawkins R (1991) The blind watchmaker (Repr. ed.). Harmondsworth, Penguin books

Dembski WA (1999) Intelligent design : the bridge between science and technology. Downers Grove, IL, InterVarsity press

Dembski WA (2002) No Free Lunch: Why specified complexity cannot be purchased without intelligence. Lanham, Ld., Rowman \& Littlefield Publishers

Dietz RS (1983) Gish's Law. Geotimes 28(8):11-12

Dunkelberg P (2003). Irreducible complexity demystified. Talk Reason, from www.talkdesign.org/faqs/icdmyst/ICDmyst.html

Forrest BC and Gross PR (2007) Biochemistry by design. Trends Biochem Sci 32(7):301-310

Forrest BC and Gross PR (2007) Creationism's Trojan horse : the wedge of intelligent design (Updated). Oxford, Oxford university press 
Kelemen D (2004) Are children "intuitive theists"? Reasoning about purpose and design in nature. [Article]. Psychological Science 15(5):295-301

Kelemen D and Rosset E (2009) The Human Function Compunction: Teleological explanation in adults. [Article]. Cognition 111(1):138-143

Lenski RE, Ofria C, et al. (2003) The evolutionary origin of complex features. [Article]. Nature 423(6936):139-144

Miller KR (2000) Finding Darwin's God : a scientist's search for common ground between God and evolution. New York (N.Y.), HarperCollins

Miller KR (2004) The flagellum unspun. The Collapse of "Irreducible Complexity". In W. Dembski and M. Ruse (Eds.), Debating design: from Darwin to DNA (pp 81-98)

Morris H (Ed.) (1974). Scientific Creationism (general edition). San Diego, Creation-Life Publishers

Muller HJ (1918) Genetic Variability, Twin Hybrids and Constant Hybrids, in a Case of Balanced Lethal Factors. Genetics 3:422-499.

Orr AH (1997) Darwin vs. Intelligent Design (again): The latest attack on evolution Is cleverly argued, biologically informed—and wrong. BRev 22(6)

Pallen MJ and Matzke NJ (2006) From The Origin of Species to the origin of bacterial flagella. Nature Reviews Microbiology 4(10):784-790

Pennock RT (1999) Tower of Babel : the evidence against the new creationism. Cambridge (Mass.), MIT press

Pennock RT (2000) Lions, Tigers and APES, Oh My! Creationism vs. Evolution in Kansas. Paper presented at the AAAS Dialogue on Science, Ethics and Religion. from http://www.aaas.org/spp/dser/02_Events/Conferences/CF_2000_04_1415_Teach/Abstract_Pe nnock.shtml

Perakh M (2002). A free lunch in a mousetrap Retrieved January 7, 2010, from http://www.talkreason.org/articles/dem_nfl.cfm\#salvage

Perakh M (2004) Unintelligent design. Amherst (N.Y.), Prometheus books

Pigliucci M (2002) Denying evolution: Creationism, scientism, and the nature of science.

Sunderland, MA, Sinauer Associates

Ratzsch D (2005) How Not to Critique Intelligent Design Theory. Ars Disputandi: The Online Journal for Philosophy of Religion 5

Roth AA (1980) Implications of the various interpretations of the fossil record. Origins 7(2):71-86 
Shanks N and Joplin K (1999) Redundant Complexity: A Critical Analysis of Intelligent Design in Biochemistry. Phil Sci 66(2):268-282

Sober E (2008) Evidence and Evolution: the logic behind the science. Cambridge, Cambridge University Press

Young M and Edis T (2006) Why intelligent design fails : a scientific critique of the new creationism. New Brunswick, N.J., Rutgers University Press 